\title{
Notas sobre la complicidad intelectual de Ricardo Palma y Juana Manuela Gorriti
}

\author{
Oswaldo Holguín Callo \\ Pontificia Universidad Católica del Perú, Lima - Perú \\ Instituto Ricardo Palma \\ oswaldoholguin@gmail.com
}

\section{Resumen}

Entre Ricardo Palma y Juana Manuela Gorriti existió una estrecha amistad durante más de cuatro décadas. Ella, quince años mayor, orientó al joven "bohemio" en sus primeros ensayos literarios; él apreció mucho su obra narrativa y la consideró parte del parnaso peruano. El artículo desarrolla algunos de los capítulos de una amistad que fue también complicidad en empresas periodísticas y culturales, como las célebres veladas literarias realizadas en Lima en 1876 y 1877.

Palabras clave

Ricardo Palma, Juana Manuela Gorriti, Veladas literarias en Lima, Tradiciones peruanas, Literatura peruana del siglo XIX

\section{Abstract}

A dear friendship existed between Ricardo Palma and Juan Manuela Gorriti, one that lasted for more than four decades. She was fifteen years his senior and guided the young bohemian man in his first literary essays. He truly appreciated her narrative work and considered her a part of the Peruvian parnassus. This article develops some chapters of a friendship that was also considered a complicity in cultural and journalistic ventures such as the well-known literary evenings in Lima in 1876 and 1877.

Keywords: Ricardo Palma, Juana Manuela Gorriti, Literary evenings in Lima, Peruvian Traditions, Peruvian Literature in the 19th century 
Oswaldo Holguín Callo es doctor en historia por la PUCP y profesor principal de su Departamento de Humanidades. Ha publicado Tiempos de infancia y bohemia. Ricardo Palma (18331860), Páginas sobre Ricardo Palma, Poder, corrupción y tortura en el Perú de Felipe II y Cafés y fondas en Lima ilustrada y romántica, y artículos en revistas del Perú y España. Ha editado Tradiciones peruanas de Ricardo Palma (Quito) y Los cronistas del Perú (15281650) de Raúl Porras Barrenechea, y coeditado La correspondencia inédita de Lola Rodríguez de Tió a Ricardo Palma... (Puerto Rico). Es miembro de número de las Academias Nacional de la Historia y Peruana de la Lengua, y del Instituto Ricardo Palma. 


\section{Introducción}

Ricardo Palma y Juana Manuela Gorriti fueron amigos durante más de cuarenta años. Juntos o como miembros de un grupo participaron en numerosas empresas y proyectos literarios y periodísticos, sociales, etc., pero solo abordaré algunos, los que revelaron una verdadera complicidad intelectual o un trabajo conjunto orientado a un fin preciso.

Los hechos se desarrollaron en Lima, desde los años 1850 y 1860, la de los presidentes Castilla, Echenique, Pezet, Prado, hasta los de 1870 y 1880, la de los gobernantes Balta, Pardo, Prado y Piérola, etc., estos últimos en los primeros años de la Guerra del Pacífico. En tan largo período, se produjeron importantes cambios sociales, como la aparición de una burguesía guanera y agroexportadora, el fin de la esclavitud y del tributo, la europeización de las élites y de los sectores medios, una sociabilidad más horizontal, el incremento del mestizaje, el papel más activo de las mujeres, etc., etc.

Los personajes son muy conocidos, pero debe recordarse que los separaban quince años pues Gorriti había nacido en 1818 y Palma en 1833. Ella era hija de un general de la Independencia argentina, nacida en Salta del Tucumán; se casó muy joven con el militar boliviano Manuel Isidoro Belzu, quien participó en diversas aventuras caudillistas, alcanzó la presidencia de su país y, más tarde, murió a manos de otro caudillo. Gorriti se separó de su esposo y se radicó en Lima aproximadamente en 1850, donde en un ambiente muy acogedor para el ejercicio de sus dotes sociales y literarias, estableció un colegio para niñas. Palma y Gorriti se conocieron por entonces; no solo la edad los separaba sino, sobre todo, muchas experiencias vitales pues él era solo un adolescente limeño, miembro de la amical y criolla "bohemia romántica" que nos ha descrito en páginas penetradas de añoranza y emoción, en tanto ella había alternado con 
personajes de su provincia y desempeñádose como esposa de un presidente boliviano.

\section{Juana Manuela Gorriti y los "bohemios"}

En Lima, Gorriti encontró facilidades para darse al placer que la embargaba, la literatura, y no solo al trabajo. Provenía de un círculo no ajeno a la buena lectura, que ella había cultivado con verdadero deleite en la lejana provincia de su niñez y juventud, como también en Bolivia, y que en el Perú seguía practicando junto a la composición literaria. Empezó a publicar sus relatos, románticos y evocadores, sentimentales y dramáticos, muy al gusto del momento, en especial sintonía con los sentimientos de las mujeres de su tiempo. Así, en 1851, en las abigarradas y poco legibles columnas de El Comercio, publicó "La quena. (Leyenda peruana)", dedicada a las limeñas en términos harto sensibleros:

Hijas de Lima, a vosotras cuya adorable bondad iguala a vuestra deslumbradora belleza, y cuya dulce voz y mano cariñosa han calmado mis penas y enjugado mis lágrimas, cuando, como el héroe de mi leyenda, vine con el corazón lleno de tristeza y desaliento a pedir a vuestro país un poco del reposo que me era negado en el resto de la tierra, a vosotras consagro este pequeño ensayo literario ${ }^{1}$,

y "El guante negro", ofrecida a los editores de El Comercio, el argentino Alejandro Villota y el chileno Manuel Amunátegui ${ }^{2}$. "La quena" cuenta la trágica historia de unos amores sacrílegos con final dantesco que Palma, años después, empleó en la tradición "El manchay-puito".

l El Comercio, Lima, 29 ene. 185 1, 3468, pp. 1 y 2, "Folletín”, y eds. ss. Suscribió la dedicatoria con sus iniciales.

2 El Comercio, Lima, 29 abr. 1852, 3834, pp. 1 y 2, “Folletín”, y ed. sgte. Suscrita con sus iniciales, desarrolla un tema argentino. 
$\mathrm{D}^{\mathrm{a}}$. Juana Manuela fue una mujer amante de la tertulia cultivada sobre materias literarias e históricas, pero no rehuía hablar de política y ocurrencias sociales. Halló en Lima a un grupo de adolescentes y jóvenes veinteañeros, los "bohemios" románticos, a los cuales atrajo y con quienes hizo muy buena amistad, acogiéndolos en su salón y alentándolos en sus incipientes tareas poéticas, dramáticas y narrativas. Propiamente hablando, no dirigió una tertulia en sentido estricto; lo que algunos admiraban en ella, lo que los atraía era que "sin escribir versos, era una organización altamente poética. Los bohemios la tratábamos con la misma llaneza que a un compañero, y su casa era para nosotros un centro de reunión", comentario palmino que confirma una nota manuscrita, inédita, de 1902: “...[desde 1851], su casa fue el centro de la juventud literaria. A ella concurríamos con entera llaneza Arnaldo Márquez, Manuel Castillo, Luis Cisneros, Clemente Althaus, Pompilio Llona, Trinidad Fernández, Fernando Velarde, Carlos Salaverry [añadido], Juan Vicente Camacho..."3.

Palma fue uno de sus más decididos admiradores, primero, y, más tarde, afectísimo amigo y camarada. En 1854, con el formalismo que correspondía, le dedicó la tradición "Infernum el hechicero", y en 1857, cuando la relación había crecido, "La venganza de un ángel. (Confidencias de un libertino)”, relatos que acompañó de sentidas frases y versos de ofrecimiento escritos de su puño y letra en el precioso álbum de la señora ${ }^{4}$, como los siguientes:

3 "La bohemia de mi tiempo, 1848 a 1860 (confidencias)", p. 14; y Biblioteca Nacional del Perú, ms. D-2394, f. s. n., respectivamente.

4 Biblioteca Nacional del Perú, ms. D-2394, ff. 87-91 y 59-61, respectivamente; y Holguín Callo, Tiempos de infancia y bohemia. Ricardo Palma (1833-1860), pp. 395396 y 397-398, respectivamente. 


\section{A Juana Manuela Gorriti \\ su mejor amigo \\ Ricardo Palma.}

Para tu álbum, amiga,

Pides un cuento

$\mathrm{Y}$ aquel que en complacerte

Cifra su intento

Ahí te lo envía...

Y que tu alma le preste

Su poesía.

Lima, octubre $23 / 857^{5}$.

El primer escrito refiere personajes y ocurrencias lindantes con el inframundo, lo sobrenatural, misterioso e inexplicable, temática romántica que a ella la atraía y a él le dio tela para más de una narración; el segundo, unos amores signados por la tragedia, muy al gusto de $\mathrm{D}^{\mathrm{a}}$ Juana Manuela, quien no era poeta sino narradora de novelitas, cuentos, leyendas, ficciones adobadas de muchos recuerdos positivos; era amiga de dar rienda suelta a la fantasía, liberada de toda limitación fijada por el trabajo riguroso de un ensayista o de un historiador. Sin duda, ella alentó a nuestro escritor en esos primeros ensayos que, más tarde, darían paso a sus celebradas tradiciones.

Angélica Palma refiere un episodio anecdótico que comprueba la estimación que la dama argentina tuvo por su padre. El "bohemio" Althaus hallábase un día en su salita

de mejor talante que de costumbre por ser el único visitante. Entró Palma, y Althaus torció el gesto; el recién llegado también lo puso hosco.

$5 \quad$ Ibíd., p. 398. 
- ¿Qué tiene usted, Ricardo?- preguntó la dueña de casa.

- Nada, señora; un ligero dolor de cabeza.

- Yo lo curaré- contestó ella sonriendo; y, después de echar sobre el pañuelo su aliento cálido, lo aplicó a la frente del joven, que muy a gusto, se dejaba mimar.

- Madame- exclamó Althaus, testigo disgustado de la escena, acentuando la impertinencia de sus frases con el empleo de idioma extraño, -ce n'est pas une femme comme vous que doit avoir ces gentillesses envers un jeunne homme. [Señora, una mujer como Ud. no debe tener esas gentilezas con un joven].

- Monsieur Althaus- respondió la literata, -ce n'est pas un enfant comme vous qui peut faire des observations a une femme comme moi; prenez mon mouchoir et mouchez vous. [Señor Althaus, un niño como Ud. no puede hacer observaciones a una mujer como yo; tome mi pañuelo y suénese $]^{6}$.

El cuadro nos alcanza algo de la personalidad de la anfitriona, de su estilo de mujer fuerte con experiencia en el trato social, desinhibido y algo bizarro, bebido seguramente en la provincia, que a Palma y a otros "bohemios" sin duda impresionó y cautivó. Pero también Gorriti sabía conducirse con la elegancia y la distinción propias de una dama familiarizada con las normas de la urbanidad aristocrático-burguesa de su tiempo. Palma tuvo que ver en ella no pocas manifestaciones de refinamiento y cortesanía, de atractivo femenino, de delicado instinto maternal.

6 Ricardo Palma, p. 72. 


\section{En La República (1863-1864)}

Una y otra vez, Palma y Gorriti compartieron o frecuentaron en Lima los mismos espacios periodísticos y literarios. Todos los que se dedicaban a esas tareas se conocían y ambos eran bastante apreciados por sus producciones y logros editoriales. Entre noviembre de 1863 y julio de 1864, salió La República, semanario político liberal dirigido por José María Químper ${ }^{7}$, de cuya sección literaria se hicieron cargo ambos colegas, quienes al punto recibieron elogios de un periodista de El Mercurio: "El nombre y la profunda imaginación de la señora Gorriti, se hallan en gran parte vinculados a nuestras glorias nacionales. La reputación del señor Palma es una garantía elocuente del tino con que se sostendrá esa sección"8. Como otros órganos de prensa contemporáneos, La República expresó un ferviente americanismo en aquellos días de desembozado expansionismo europeo. Allí publicó Palma la magistral tradición "Don Dimas de la Tijereta” (1864), cantares amorosos y gacetillas no ajenas a la intención política de cierta moderada oposición.

$\mathrm{D}^{\mathrm{a}}$. Juana Manuela se apartó del Perú en los siguientes años y estuvo en Bolivia cuando asesinaron a su esposo (marzo de 1865); de retorno en Lima, se identificó con el Perú cuando la malhadada expedición-invasión española de 1864-1866, reuniendo algunas composiciones patrióticas en Corona poética ofrecida al pueblo peruano el 28 de julio de 1866 (1866). A poco, la muerte le arrebató a dos de sus menores hijos (1867) y Palma se asoció a su pesar con una sentida octava que nos deja más de una pregunta sin respuesta:

"Fraternidad"

A J. M. G.

7 Paz Soldán, Biblioteca peruana, p. 58

8 El Mercurio, Lima, 16 nov. 1863, 324, p. 3. 
Yo quiero del cáliz

amargo libar que hoy apuras;

mi parte en tus penas

yo debo también reclamar.

Unidos pasamos

las horas de inciertas venturas...

iAh! no te abandono

si toca a tu puerta el pesar.

Lima, $1867^{9}$.

Palma no dejó de brindarle su apoyo intelectual y se convirtió en uno de los colaboradores de El Álbum. Revista semanal para el bello sexo, dirigida por ella y la tacneña Carolina Freire de Jaimes (1874-1875), así como de La Alborada. Semanario de las familias (1874-1875), redactado por muchas señoras, entre ellas Gorriti, publicaciones de solvente gestión femenina.

\section{La "Carta tónico-biliosa a una amiga" (1874)}

El gran suceso literario que fue la publicación de la primera serie de las tradiciones en 1872, animó a D. Ricardo a lanzar la segunda en 1874. Al frente de sus animados relatos, puso una "Carta tónico-biliosa a una amiga" (Lima, mayo de 1874), la señora Gorriti, larga poesía festiva y sin tapujos en la cual expresó su interés por el pasado y refutó a sus críticos, los reales y los posibles... Cuando Palma la bautizó como carta "tónicobiliosa" seguramente quiso decir que se trataba de una misiva escrita con vigor y genio destemplado, con fuerza y mal humor, cosa que en cierta forma confirma su lectura ${ }^{10}$.

9 Pasionarias (1870).

10 "Carta tónico-biliosa a una amiga". 
Palma celebró que $\mathrm{D}^{\mathrm{a}}$ Juana Manuela leyera sus tradiciones y por ello, y por la sincera amistad que los ligaba, le confió sus pensamientos:

Leyendo mis tradiciones

me dicen que te complaces.

iGracias! iGracias! Pues tal haces

a ti van estos renglones.

Charlemos en puridad

un momento:-oye con calma-

dar quiero expansión al alma

en tu sincera amistad.

Por entonces, Palma recusaba los fictos lamentos del romanticismo y creía que los sufrimientos debían guardarse en el corazón:

Arca santa el corazón

sea de los sufrimientos:

darlos a los cuatro vientos

es una profanación.

Por ello y por saber que su amiga había sufrido mucho, le dijo:

Tú sabes bien que el dolor, si es verdadero y profundo, ha de esconderse ante el mundo con cierto noble rubor.

iTú que la cruz arrastrando vas de un padecer tremendo, con los labios sonriendo, con el corazón llorando! 
Gorriti, en efecto, había sufrido mucho: la violenta muerte de su marido y la prematura de sus hijos. Si hubo otros contrastes, aún no han sido desvelados.

Las siguientes cuartetas las empleó D. Ricardo en justificar su culto del pasado, su literatura de entraña histórica:

¿Por qué escribo estas leyendas?

¿Por qué de siglos difuntos

dan a mi péñola asuntos

las consejas estupendas?

La exitosa fórmula literaria que había creado, celebrada por propios y extraños, pues ya eran varios los tradicionistas de aquende y allende, le hacía creerse un hombre dotado de un talento especial para recrear la historia:

¿Quién sabe si mal mi grado,

(todo puede suceder)

llevo escondida en mi ser

la intuición de lo pasado?

Ese éxito también justificaba su alejamiento de los problemas presentes y su entrega plena a la literatura: "Hastiado del presente, me he echado a vivir en el pasado rebuscando antiguallas y disputando a la polilla libros viejos. La conciencia me dice que acaso hago en esto un servicio a mi país", le confesó por entonces a su amigo Juan María Gutiérrez, notable literato argentino ${ }^{11}$.

Palma pensaba que hacía obra patriótica y cívica, que con su libro daba lecciones al presente y al porvenir y, sin pérdida de tiempo, aprovechó la ocasión para recusar a quienes no lo entendían:

11 Epistolario, 1, p. 15. 
Vanidoso desahogo

encontrará un zoilo en esto

y murmurará indigesto:

-¿quién lo ha hecho a usted pedagogo?

No se queme las pestañas

descifrando mamotretos

sobre tiempos y sujetos

que alcanzó Mari-Castañas.

En cambio, el presente le parecía vacío e insulso:

Hoy ya no inspira entusiasmo

lo serio, sino el can-can,

y en leal consorcio van

la duda con el sarcasmo.

Hoy es el mercantilismo

la vida del pensamiento;

es Dios el tanto por ciento

y es su altar el egoísmo.

iSon nuestros tiempos fatales!

Por eso, por eso vivo

hecho un ambulante archivo

de historias tradicionales.

En fin, hizo relación de los muchos yerros que sus críticos encontraban en sus tradiciones, de toda monta y grado, pero ello no le impidió expresarse con desenfado y lisura -“...he desfogado mi bilis... Basta de jaculatoria”-, señal de lo poco que le importaban esas observaciones:

¿Qué mucho si me hace añicos

un crítico y si me ultraja, 
siendo en la humana baraja

yo de los triunfos más chicos?

\section{Las veladas literarias (1876-1877)}

La señora Gorriti era una mujer de trabajo que hallaba satisfacción en la educación de niñas y adolescentes, actividad que le brindaba los recursos que su familia requería. En los años 1870, estableció un nuevo colegio femenino de más envergadura y alcances. Fue entonces que decidió organizar en el salón de su casa, en la calle de Urrutia (séptima cuadra del jirón Camaná), las veladas literarias que la hicieron famosa. Angélica Palma, informada por su padre, la presenta así:

...alta, muy delgada, con abundantes mechones de canas plateándole los cabellos rubios, escudriñadoras en las cuencas profundas de los ojos las claras pupilas, efusiva en el trato, de palabra fluida, la dueña de casa encarnaba la persistencia del romanticismo literario en los momentos del avance victorioso del naturalismo ${ }^{12}$.

En Lima, los círculos cultos y los de elevada posición social apreciaban las tertulias literarias y musicales que hacían posible la presentación de diversas formas y estilos en prosa y verso, así como la ejecución de piezas musicales de autores nacionales y extranjeros. En los años 1870, quizá los más felices en la vida de los limeños del siglo XIX, algunas familias burguesas convirtieron sus salones en verdaderos escenarios de exposición del saber, donde los ingenios de la época hacían públicas sus producciones, es más, solían recibir un día de la semana, en forma habitual, a parientes y amigos que animaban reuniones orientadas al disfrute artístico, a la conversación ideológica, al

12 A. Palma, "Veladas del ochocientos", pp. 191-192. 
juego ingenioso, etc. ${ }^{13}$. Gorriti, bien relacionada con muchos intelectuales en boga, vio la singular oportunidad que se le ofrecía para organizar unas veladas de muy buen nivel literario y musical con la participación de sus amigos y amigas, y así se convirtió en la anfitriona de selectos grupos mixtos, en su mayoría jóvenes o maduros, amantes de la música, la poesía, el ensayo, la novela, etc., los cuales dieron vida a una larga serie de aplaudidas veladas entre julio de 1876 y julio de 1877 , cuando viajó a Buenos Aires. Los concurrentes a las veladas, "verdaderas lides en que las armas del talento y del ingenio se disputaban el lauro" (Palma), eran "señores de levita negra y corbata de lazo, damas con trajes de puff y cola, con peinados complicados de trenzas y bucles y alhajas con aderezos de granates o guardapelos de oro, pendientes de aterciopelada cinta negra, realzadora de la morbidez de la garganta"14. El programa incluía "recitales de poesía, lectura de cuentos y ensayos, ejecuciones en piano y violín de obras musicales tanto cultas como populares (allí se pusieron en boga los yaravíes), interpretación de canciones, juegos y charadas, para terminar en una tertulia que se prolongaba hasta altas horas de la madrugada"15. Abelardo Gamarra dejó descrita la mecánica de los encuentros:

Las veladas tenían tres partes: de nueve a once, las señoras en un salón y los caballeros en otro, departían a su sabor y tijereteaban a su gusto; de once a una se ejecutaba el programa, caballeros y señoras en un solo salón; de una a dos se retiraban los que temían constiparse, y de dos en adelante, como después de las topadas de gallos suelen venir las jugadas de chuscos, daban principio las chuscadas, las

13 Véase Holguín Callo, "Política y literatura en un impreso limeño de 1876 ", y Varillas Montenegro, "Política y cultura en una década de esplendor, la de 1870".

14 A. Palma, Ricardo Palma, p. 73.

15 Salas Guerrero, "Juana Manuela Gorriti y el Perú", pp. 91-92. 
poesías del género epigramático, las anécdotas picarescas, las letrillas, las improvisaciones, las diabluras de ingenio.

Era la golosina de la tertulia, y la señora Gorriti, que en la primera parte había sido la señora de la casa, la gran señora por sus maneras, comedimientos y atención y en la segunda se mostraba la literata de fuste, la escritora de vastísima ilustración, era en la última parte la musa tentadora de las mataperradas, la reina de la gracia, la espiritual decidora de las agudezas inimitables ${ }^{16}$.

El periodismo local dio amplia cobertura a las veladas, un ejemplo: "Espléndida fue la velada literaria que tuvo lugar anoche en los salones de la señora Gorriti. Baste decir que lo más selecto de nuestros escritores y poetas nacionales estuvieron presentes..."17. Otro, no ajeno al orgullo nacionalista: las personas que participan "en estas fiestas de la inteligencia han obtenido un nombre envidiable en la República de las letras y con lógica incontestable de los hechos ponen de manifiesto el progreso que ha alcanzado la literatura nacional contribuyendo al esplendor del Perú"18.

Palma fue uno de los animadores principales de las veladas y asistió a muchas porque pasaba por un excelente momento de producción intelectual y sus relaciones con la sociedad culta de Lima no podían ser mejores. Su talento le había ganado un prestigio que los zoilos no podían disminuir. Presentó trabajos en la mayoría de ellas: algunas poesías propias o traducidas de Heine y, sobre todo, numerosas tradiciones, las más originales,

16 Abelardo Gamarra, prólogo a Lo íntimo, Buenos Aires, Ramón Espasa, 1897, p. 10, cit. por Batticuore, El taller de la escritora, p. 25.

17 El Comercio, Lima, 10 ago. 1876, cit. por López Martínez, Sucedió hace un siglo. Segunda serie, p. 87.

18 El Comercio, Lima, 30 nov. 1876, cit. por Batticuore, El taller de la escritora, pp. 208-209. 
las cuales eran muy solicitadas y esperadas. Además, leyó un ensayo feminista ("Trabajo para la mujer") de Teresa González de Fanning (María de la Luz) y un artículo costumbrista -"Juan Carmelo"- a pedido de su autor y amigo Manuel Atanasio Fuentes, el Murciélago. En cierta ocasión, Mercedes Cabello de Carbonera, proclamada en un juego "reina de la Haba", ordenó a su ministro de Gobierno (Palma) leer un nuevo producto de su pluma, orden que el obediente súbdito se apresuró a cumplir presentando dos tradiciones, las que fueron "aplaudidas con entusiasmo". Por cierto, los críticos no le escatimaron elogios:

Ricardo Palma ha leído dos nuevas tradiciones tituladas, una, "La fruta del cercado ajeno", y, la otra "Desdichas de Pirindín", precedidas ambas de una linda poesía de circunstancias, que mereció una salva de aplausos. Los escritos de Palma no necesitan encomios; llevan en sí mismos el sello de su mérito incuestionable, y solo basta mencionarlos para creer que en ellos abunda la originalidad, la sal y la gracia en el decir, a la par de la elegancia de la forma y la magnífica corrección del lenguaje ${ }^{19}$.

Por aquellos felices años de la preguerra con Chile, algunos jóvenes y talentosos provincianos llegaron a Lima, de visita o para establecerse, siendo acogidos por las élites intelectuales. Palma no rehuyó ofrecerles su respaldo. Así, en una velada ad hoc se produjo el "bautizo" literario del escritor huamachuquino Abelardo Gamarra; junto a los "bohemios" Manuel Adolfo García y Acisclo Villarán, Palma determinó su nuevo seudónimo: El último Harabicu y ofició de párroco bautista, escribiendo al efecto una "Exortación [sic] y bautizo" que, entre otras cosas, decía:

19 Alejandro Cerdeña en Gorriti, Veladas literarias de Lima, p. 323. 
Estampa tendré yo de mamarracho

o bien de monigote

cuando, sin respetar este mostacho, me hicieron sacerdote.

En el nombre de Apolo y de las Musas

yo bautizo a este chico

llamándolo, sin más recancamusas, El último Haravico ${ }^{20}$.

Y, por febrero de 1877, asistió a la velada en la que fue distinguida la joven escritora cuzqueña Clorinda Matto de Turner, leyendo entonces la tradición "La procesión de ánimas de San Agustín”. La señora Matto era muy apreciada por sus relatos, especialmente por sus tradiciones según el modelo de Palma, a quien le había dedicado la titulada "Tambo de Montero" (1875), correspondida por Palma con "iBeba, padre, que le da la vida!".

Palma también participó en las veladas que tuvieron como invitados especiales a viajeros e intelectuales extranjeros de paso por Lima, como el cubano José Joaquín Palma; el argentino Pastor S. Obligado, también tradicionista, quien leyó la que le había dedicado ("Una procesión en 1592"); y el español Juan Martínez Villergas, escritor satírico y de combate, a quien el tradicionista había conocido en su primer viaje a Europa, lo que recordó en una versada/oda de "Intimidades" y bienvenida:

Han corrido doce años desde el día

en que, en tierra anglicana,

nos uniera amistosa simpatía,

exenta de lisonja cortesana.

20 Ibíd., pp. 433 y ss., 468 y 469. 
Yo era un pobre muchacho sin historia,

mal rimador y pésimo prosista,

y ya tú, por derecho de conquista,

gozabas en las letras de alta gloria. 21.

Palma recordó la amistad y consejos con que desde hacía diez años lo honraba el literato hispano "e hizo presente que en el Perú existe una juventud dotada de clara inteligencia y entusiasta por el progreso de las letras, juventud que ha menester buenos modelos y que recibirá con placer la enseñanza del buen maestro, señor Villergas"22.

Como es sabido, en las veladas desempeñaron un papel sumamente importante las no pocas mujeres literatas que vivían en Lima: Mercedes Cabello de Carbonera, Manuela Villarán de Plasencia, Rosa María Riglos de Orbegoso, Juana Manuela Lazo de Eléspuru, Carolina García de Bambarén, Mercedes Belzu de Dorado, hija de la anfitriona, Teresa González de Fanning, Juana Rosa de Amézaga, Adriana Buendía, Mercedes Eléspuru, Justa García Robledo, etc., así como no pocas cultoras de la música (cantantes y ejecutantes), pues Gorriti, educadora de niñas y adolescentes, se había propuesto promover y difundir el talento femenino haciendo participar a sus mejores exponentes y publicando ensayos de autores varones y mujeres sobre la materia. Palma no fue ajeno a esa campaña y produjo unas "Estrofas" en las que colmó de elogios a la pianista Rosa Ortiz Zeballos de Raborg, a la cantatriz Cristina Bustamante, a la poetisa Manuela Villarán de Plasencia, a la ensayista Mercedes Cabello de Carbonera y, ciertamente, a la anfitriona. Pero fue su poesía "En una tertulia literaria" el testimonio más claro de su adhesión a las jóvenes escritoras y, sobre todo, a la organizadora de las veladas:

21 Verbos y gerundios, p. 145.

22 Crónica de El Comercio cit. por Batticuore, El taller de la escritora, p. 205. 
Aún vibran en el alma las gratas impresiones de la última velada que aquí nos reunió: aún siento en mis oídos las notas delicadas que una hada al piano flébil enérgica arrancó. (...)

Modesta poetisa de las sencillas frases [Manuela Villarán de Plasencia], no tengo yo coronas para adornar tu sien: tus versos son violetas henchidas de perfume; acepta de mis labios sincero parabién. (...)

Con galas académicas, con varonil firmeza [Mercedes Cabello de Carbonera], con inspiradas formas, oyó esta reunión hacer la apología del arte y de las letras, glorificar de Homero la magna creación. (...)

Y a ti, mi noble amiga, mi hermana por el arte, a ti, la iniciadora de esta brillante lid [Juana Manuela Gorriti], en donde solo triunfos cosecha el entusiasmo, en donde de la envidia no silba el fiero aspid;

Decirte puedo solo que á tu corona añades laureles que no el tiempo procaz marchitará; tu nombre, más que tuyo ya es nombre americano; tu gloria, más que tuya de América será.

Señoras: a mi pluma prosaica y nada seria, benévolas quisisteis poner contribución: mandáis, a quien de dócil a vuestra ley se precia; mandáis, y os obedece contento el corazón.

Olor a pergamino guardado en arca vieja traspiran las consejas que a relataros voy: 
perdón, si poesía no hayáis en mi palabra;

benevolencia os sobra. . . tomadme como soy. ${ }^{23}$

Más tarde, iba a recordar con nostalgia el brillante papel que las hijas de Eva desempeñaron en esas reuniones:

Nada me impide llevar la flor del recuerdo a la tumba de las nobles amigas que fraternizando en ideales con la digna madre de usted [Julio J. Sandoval], fueron el encanto de aquellas deliciosas noches, de cordiales, de íntimas espansiones [sic], gozadas en el modesto, a la vez que elegante salón de la ilustre literata argentina ${ }^{24}$.

Como debía ser, fue principalísimo el papel de $\mathrm{D}^{\mathrm{a}}$ Juana Manuela en las veladas, traducido en el estímulo, el aliento y la confianza que puso en las damas escritoras que animaron con su figura y su talento las gratísimas e inolvidables reuniones:

Pero fue sin embargo en el caso de las mujeres donde se advierte con mayor claridad el papel trascendente que cumplió la Gorriti en las letras peruanas, dado que muchas escritoras que recién empezaban las tareas literarias encontraron el espacio donde desarrollar su carrera gracias al auspicio que recibieron de la novelista argentina. Es el caso de nuestras dos principales novelistas del siglo XIX: Mercedes Cabello de Carbonera y Clorinda Matto de Turner ${ }^{25}$.

Por cierto, entre los participantes hubo varios "bohemios": Manuel Adolfo García, Numa Pompilio Llona, Acisclo Villarán, Clemente Althaus, etc., así como escritores más jóvenes: Ricardo Rossell, Pedro Antonio Varela (El Chico Terencio), Abelardo

23 Poesías (1887), pp. 433-435.

24 "[Carta-prólogo]", p. vi.

25 Salas Guerrero, "Juana Manuela Gorriti y el Perú”, p. 99. 
Gamarra, Modesto Molina, Teobaldo Elías Corpancho, entre otros.

\section{La Guerra}

Gorriti conoció el rancho de Palma en Miraflores, pueblo que visitó muchas veces atraída por su clima, campiña y sociedad. Su libro El mundo de los recuerdos contiene un capítulo dedicado al encantador balneario de Lima, a sus habitantes y huéspedes, en el que no hizo faltar una alusión a la rica biblioteca de Palma ${ }^{26}$.

En los días de la Guerra con Chile, Gorriti se identificó plenamente con el Perú, celebró sus victorias y lamentó sus derrotas, pasando incluso momentos de verdadero apremio, pero como la situación en Lima ocupada por el enemigo cambiara radicalmente, decidió alejarse y establecerse en Buenos Aires con su hijo y su nuera. Durante mucho tiempo, ella pensó retornar al Perú, lo que finalmente no pudo realizar. En esos años difíciles, Palma debió de serle deudor de muchos favores, como el relacionarlo con los periódicos e intelectuales argentinos que podían brindarle alguna ayuda económica, y por ello le dedicó "Amor de madre" (1883) ${ }^{27}$, lo que la convirtió en la única persona a quien Palma le dedicó tres tradiciones. A su turno, Da Juana Manuela le ofreció "El banquete de la muerte", episodio de la historia boliviana ocurrido en Oruro (1835-1836), en el cual ella participó, relato recogido en su El mundo de los recuerdos.

Cuando D. Ricardo escribió "La bohemia de mi tiempo" (1886), consagró a su cómplice intelectual un párrafo especial con motivo de recordar la publicación de su novela "La quena".

26 En Gorriti, 2017 b, "Miraflores».

27 En 1874, dedicada a Juan Francisco Pazos. 
Ganado por el aprecio y la simpatía, afirmó allí que "La quena" produjo una tormenta de críticas porque los mojigatos la consideraron "inmoralísima", pero que, después de María de Jorge Isaacs, era "la más bella novela que se ha escrito en América latina" 28 . La novela no ha merecido elogios de la crítica, por ello es evidente que los conceptos de D. Ricardo fueron fruto del gran afecto que le tuvo a su autora. Tan presente la tenía, sin embargo de su origen y alejamiento del país, y no solo de su condición femenina, que la consideraba parte de "la bohemia" limeña: la señora Gorriti, Llona, Márquez, Lavalle, Cisneros, Paz-Soldán y yo, "somos, de la antigua bohemia, los que aún peleamos la batalla de las letras y permanecemos firmes en la brecha, alentando a la juventud llamada a relevarnos y dándola por toda consigna esta palabra: perseverancia" $(1886)^{29}$. En el siguiente año, Clorinda Matto de Turner, estimulada por Gorriti desde la Argentina, inició otro ciclo de veladas literarias asegurando que eran continuadoras de las que aquella realizara una década antes; pues bien, en la primera reunión (12 de noviembre de 1887), Palma le rindió homenaje con la poesía "En una velada literaria. En obsequio de la señora Gorriti, residente en Buenos Aires", donde volvió a considerarla escritora peruana e hizo memoria del reconocimiento que sus obras le merecieran:

iOh, gracias! Esta noche despierta en mi memoria memorias adormidas de tiempo más feliz, en que una noble dama, de nuestras letras gloria, brindábame laureles, en literaria lid.

Ausente en las regiones que riega el ancho Plata, hoy llévenla, en sus alas, las brisas del Rímac,

28 "La bohemia de mi tiempo..." p. 13.

29 Ibíd., p. 70. 
como perfume grato que nuestro amor dilata, saludos cariñosos y ofrendas de $\operatorname{amistad}^{30}$.

\section{Correspondencia}

Radicada en Buenos Aires, Gorriti mantuvo una constante correspondencia con Palma durante nueve años (1882-1891). Las cartas de Gorriti a Palma (53), publicadas hace algunos años por Graciela Ada Batticuore con la ayuda de César Salas, se conservan en la Colección Palma de la Biblioteca Nacional, lástima que tachadas en gran parte por la censura que su hijo ejerció en ellas para que la posteridad no conociera ciertas noticias y comentarios sobre personas del mundillo social y literario, transmitidas a su colega peruano. Son misivas que comprueban el gran aprecio que le profesaba a Palma, el íntimo conocimiento de sus afectos y fobias, de su personalidad y de su temperamento. En tan interesantes misivas, Gorriti le contaba planes, proyectos, penas y multitud de noticias sobre temas caros a los dos, haciéndolo en muchos casos su confidente y no solo su cómplice intelectual. Sus también amigas epistolares Mercedes Cabello y Clorinda Matto surgen una y otra vez como reconocidos actores del trágico escenario de los años de la posguerra. Gorriti, sabedora del aprecio que a Palma le tenían los periódicos argentinos y uruguayos, se hizo mediadora privilegiada entre el público lector y el escritor limeño, transmisora de sus producciones, y hasta empleó su nombre para referir alguna anécdota que fue muy celebrada por tres medios de prensa de Montevideo ${ }^{31}$.

30 Sotomayor Martínez, Pensar en público. Las veladas literarias de Clorinda Matto en la Lima de la posguerra (1887-1891), pp. 54-55; y, con el título ligeramente cambiado, en Palma, Poesías completas, pp. 261-262.

31 Gorriti, Cincuenta y tres cartas inéditas a Ricardo Palma, p. 28. 
1888 fue un año especialmente duro para D. Ricardo por los inesperados ataques recibidos de Manuel González Prada en su discurso del Teatro Olimpo, aquel en el cual dijo que en la prosa reinaba "siempre la mala tradición, ese monstruo engendrado por las falsificaciones agridulcetes de la historia y la caricatura microscópica de la novela". A esas críticas, como sabemos, se sumaron las de los seguidores de Prada, jóvenes que acompañaron a su líder sin advertir que había un fondo de naturaleza personal en los ataques. Palma sufrió mucha amargura y la comunicó a algunos corresponsales extranjeros: Gustavo de la Fuente, Juan Luis Arteaga, los chilenos Eduardo de la Barra, Carlos Toribio Robinet y José Toribio Medina, el español Manuel Tamayo y Baus, etc., quienes le contestaron con palabras de solidaridad y condena a sus jóvenes detractores limeños ${ }^{32}$. La argentina expresó lo que Palma quería oír y era verdad:

Pero, ¿quién, en nuestro tiempo, ha visto su nombre llevado tan lejos en alas del entusiasmo? U. y nada más que $U$. Yo quisiera que esos pobres diablos miraran, aunque fuera por el ojo de una aguja, los homenajes que se hacen aquí [Buenos Aires] a U. y hasta a la menor de sus producciones. Entonces sí, babearán de rabia ${ }^{33}$.

El respaldo a su amigo no era nuevo. En sus misivas, $\mathrm{D}^{\mathrm{a}}$ Juana Manuela solía referir con insistencia

El éxito insuperable del escritor peruano, precisamente en un momento en el cual Palma comenzaba a ser cuestionado en su país por los miembros de una generación que se presentó entonces como adversaria del movimiento romántico y sus últimos representantes ${ }^{34}$.

32 Miró, Don Ricardo Palma, el patriarca de las tradiciones, p. 139.

33 Gorriti, Cincuenta y tres cartas inéditas a Ricardo Palma, p. 55.

34 Batticuore y Zuccotti, "Papeles de entrecasa. Juana Manuela Gorriti", p. 4. 
Gorriti, receptora inmediata de las obras que por esos años publicaba Palma en Lima, las leía con fruición y las difundía entre sus amigos porteños, les hallaba novedades -"hanme parecido [sus tradiciones] de un nuevo sabor en Ropa vieja"35 y, complacida, le expresaba a su autor lo mucho que eran apreciadas en la capital argentina:

iPor Dios que, gracias a U., Buenos Aires está entregado a la Ropa vieja! Nunca vi libro que levantara tan halagüeña polvareda para su dichoso autor. El Nacional reprodujo anoche "El santo y seña de Sucre" ["Pan, queso y raspadura"], que se leyó en el círculo que cada noche se reúne en mi comedor. Es imposible describir el efecto que hizo en los oyentes. Creo que la proclama del general Lara, así como los hizo torcerse de risa los habría llevado, en caso dado, a ejecutar las hazañas de los zambos del espantajo: tanto los arrebató de entusiasmo ${ }^{36}$.

\section{"Ricardo Palma" (1888)}

Quizá para levantarle el alicaído ánimo a su decepcionado compañero de lides literarias, en 1888 Gorriti escribió una ligera semblanza de Palma para acompañar su retrato publicado en el Almanaque sud-americano para el año 1889, precioso tomito ilustrado que anualmente editaba en Buenos Aires el español Casimiro Prieto y Valdés para la empresa Ramón Espasa y Cía. ${ }^{37}$. El breve texto, no referido por ningún estudioso peruano, es un hallazgo que me place presentar en esta incompleta reconstrucción (anexo). En el retrato, D. Ricardo figura muy circunspecto, con corbata de lazo, anteojos y sus característicos bigotes. Primeramente, Gorriti reparó en que la mejor edad

35 Gorriti, Cincuenta y tres cartas inéditas a Ricardo Palma, p. 84.

36 Ibíd., pp. 87, 104 y 106.

37 Ver "Ricardo Palma (1888?). 
había pasado para su amigo, pero "el alma del galano poeta guarda una juventud, una frescura que desbordan en su trato, en su pluma, y se reflejan en sus producciones más serias"; a tales virtudes, sumó "una grande energía, un austero estoicismo y una fuerza de voluntad incontrastable" 38 . Debo destacar que este retrato moral de Palma lo hizo quien conocía muy bien al retratado por una amistad de casi cuarenta años. No menos relieve tiene el recuerdo que dedica a los trágicos sucesos del día 15 de enero de 1881, la batalla de Miraflores, en la vida de Palma, su esposa e hijos:

... el enemigo avanzaba sobre la fuerza de reserva situada en los reductos delante el [sic] pueblo de Miraflores, cuyos habitantes, mujeres y niños, huían despavoridos ante las bombas incendiarias, Palma, desde los reductos, mandaba prohibir a su esposa el abandonar esos muros que los suyos estaban defendiendo, y la ordenaba aguardar en su hogar la victoria o la muerte.

Y cuando la aterrorizada joven, huyendo de su casa, saqueada y entregada a las llamas, con sus pequeños hijos en los brazos, llegaba a Lima a pie y exhausta de cansancio, él, cumplido hasta el fin el deber patrio, se reunió a ellos, serena la frente, fuerte el corazón, como en los días de la prosperidad $^{39}$.

Como podemos apreciar, Gorriti brindó información única e irrepetible, proporcionada por su biografiado o bebida de fuente próxima a los hechos, pues por entonces se hallaba en Lima y también llegó a sufrir los efectos del desastre de Miraflores. Sin pretender examinar la veracidad de su testimonio, es evidente que quiso exaltar el patriotismo de su amigo, mostrarlo como 
hombre capaz de sacrificar a su familia por el cumplimiento del deber de defender Lima. Su relato presenta a un hombre confiado en la victoria, determinado a vencer o morir antes que a rendirse o desertar, todo un soldado valeroso y abnegado. El perfil no está lejos del que solía dar a sus héroes y arquetipos legendarios y caudillescos; sin embargo, es verdad que hoy pocos suscribirían su admiración a lo que se llamaría un acto de demencial confianza que puso en gravísimo riesgo a una familia.

Por ese tiempo, el nacimiento de Cristián Palma suscitó en $D^{a}$ Juana una expresión de íntima alegría vertida en una carta (Buenos Aires, 17 mar. 1889) a su dilecta Clorinda Matto de Turner, madrina de la criatura: "Según tu citada carta, la palmera madre estará con un precioso retoñito en brazos, con grandes celos de Madame Staël, Cervantes, Victor Hugo y... quien sabe hasta el viejo palmero, a quien has de saludar en nombre mío" ${ }^{40}$. Gorriti había rebautizado a los hijos de su colega limeño: Clemente era Cervantes, Angélica era Mme. Staël, Ricardito era Victor Hugo, las "palmeritas” que solía evocar cariñosa y familiarmente en su correspondencia.

\section{Cocina ecléctica (1890)}

Gorriti publicó en Buenos Aires y 1890 un curioso libro de recetas culinarias que tituló Cocina ecléctica, reunión de varias decenas de fórmulas proporcionadas por sus amigas argentinas, peruanas, bolivianas, etc. Al nutrido elenco se incorporó su querida Cristina Román de Palma con la receta de la pachamanca; conozcamos solo el final, pues preparar la receta requiere, por decir lo menos, tanto trabajo que el mejor chef se resistiría a ejecutar:

40 (Gutiérrez de Quintanilla), Cristián por Ricardo Palma y Cristina Román de Palma. Lima, abril II de 1889, p. 13. 
Este asado indígena es esencialmente usado en meriendas campestres, bajo la fronda, sobre el césped, donde el blanco mantel, el dorado pan, las coloreadas salsas, y las garrafas de rica chicha, mezcladas a las polvorientas botellas de los venerandos añejos, hacen de esta confección culinaria nacional, un manjar exquisito. Como lo dice su nombre, pachamanca - Banquete de la Madre Tierra- es de origen incásico, y estaba reservado a la mesa del soberano ${ }^{41}$.

Aunque D. Ricardo dijo ignorar la receta de su esposa -"veo que hasta mi mujer ha resultado cocinera sin yo saberlo..."-, posiblemente no fue ajeno a la fórmula culinaria o, sobre todo, a su redacción, pues esta se aprecia sobria y elegante. No digo que $\mathrm{D}^{\text {a }}$ Cristina no escribía bien, solo digo que su marido lo hacía mejor... Gorriti le pidió una reseña, pero él contestó que era más aficionado al comedor que al fogón, "un libro de cocina no me inspira" ${ }^{42}$. Y debía ser verdad porque, aunque las tradiciones están sembradas de referencias y menciones culinarias, se deja extrañar el texto que aborde el tema con más delectación y curiosidad, ausencia quizá debida a la ruptura con el costumbrismo.

\section{"Carta-prólogo" (1892)}

En la vida de Palma, muy tempranamente llegó el tiempo de los gratos recuerdos, amables, fraternos, sinceros, pero tristes, los cuales se presentaron con bastante frecuencia a partir del medio siglo de su vida, bien sea por el inexorable paso del tiempo, bien sea porque la Guerra liquidó para siempre el tiempo feliz, muy feliz, que la antecedió. Por su parte, en los últimos años de Gorriti (+1892) abundaron los alifafes y las enfermedades, achaques que la pusieron en trance de despedirse de los suyos

41 Román de Palma, "Pachamanca”, p. 118.

42 Carta de Palma a Gorriti, de Lima y 10 nov. 1890. 
ante cada recaída. En los primeros meses de 1891, su postración presagió el final; Palma así lo refirió:

El último vapor del Estrecho nos ha traído una triste noticia: Juana Manuela Gorriti quedaba moribunda, en Buenos Aires. Era yo colegial, tenía 18 años, y desde entonces, la friolera de cuarenta febreros, data nuestra amistad. Dentro de tres días llega vapor, y tiemblo al pensar que puede traerme la triste noticia de su muerte. Pérdida, y grande, harán las letras americanas con la desaparición de esa clarísima inteligencia. Juana Manuela, pasa de los setenta, como Guillermo Prieto, y a esa edad toda dolencia alarma. ${ }^{43}$

Paradójicamente, en esos años también surgieron varios proyectos editoriales. $\mathrm{D}^{\mathrm{a}}$ Juana Manuela planeó publicar varios libros, uno de ellos conteniendo los trabajos, literarios y de otra índole, presentados en sus veladas limeñas. Los materiales de las diez primeras fechas, de alrededor de treinta, fueron recogidos en un bello libro que vio la luz en Buenos Aires en 1892; su hijo Julio F. Sandoval lo sacó de la imprenta, pero falleció antes de publicar el segundo volumen (Palma). Palma fue requerido para escribir el prólogo, pero lo que hizo, días antes de viajar a España para asistir a las celebraciones del cuarto centenario colombino, fue una carta-prólogo dirigida a Sandoval (Lima, 15 de junio de 1892), una misiva traspasada de emoción y de añoranzas suscitadas por el contenido del libro ${ }^{44}$. Palma confesó las gratas impresiones que le produjo su lectura, pero también su incompetencia para prologarlo:

El libro que, en capillas, tuvo usted la amabilidad de enviarme, ha producido en mi espíritu el mismo efecto que el refrigerador rocío sobre la planta próxima a agostarse

43 Epistolario, 1, pp. 232-233.

44 "[Carta-prólogo]". 
por el calor tropical. Indescriptibles recuerdos de tiempos ya idos palpitan para mí en las páginas del precioso libro, y por ello convendrá usted conmigo en que soy el juez más desautorizado y menos competente para hablar de su mérito literario con tranquilo e imparcial criterio. Como que yo mismo tendría, en no raras ocasiones, que ser tribunal y sujeto justiciable.

Además, el corazón no es literato, ni sabe letra de estética: no raciocina ni discute: siente y ama porque sí quand méme y esta, con frecuencia caprichosa frase, es para él la razón de las razones, ante la cual no pesan argumentos sólidos. Por eso me declaro inhábil, hasta estúpido, para escribir sobre este volumen el prólogo literario que, de mi buena voluntad por complacerlo, ha solicitado usted ${ }^{45}$.

Prefirió dedicarles algunos emocionados recuerdos a las damas escritoras, ya difuntas, que hicieran la delicia de las veladas:

iNi cómo olvidar a Cristina Bustamante, la hada gentil de rizos cabellos y ojos fascinadores, que tan melódicos trinos arrancaba de su garganta de ruiseñor; a Rosa Mercedes Riglos de Orbegoso, la aristocrática dama, cuya pluma nos embelesaba con escritos de académica corrección; a Rosa Ortiz de Cevallos, la magistral pianista; a Victoria Domínguez, la risueña joven, que cambió en breve su corona de azahares por las amarillentas flores del sepulcro; a Manuelita V. de Plasencia, la dulce poetisa de las sencillas frases, corazón de ángel encarnado en la más simpática de las mugeres [sic]! ${ }^{46}$.

45 Ibíd., p. v.

46 Ibíd., pp. v-vi. 
El ejercicio evocador le permitió constatar cómo "pocos quedamos en pie de aquella pléyade entusiasta de luchadores que hicieron de las amenas tertulias de Juana Manuela Gorriti animado palenque de literarias contiendas".

¡Cómo olvidar a Adolfo García, el poeta de calderoniana entonación, sobre quien tan cruelmente pesaron las desventuras, ni al chispeante crítico español don Juan Martínez Villergas, ni al decidor Murciélago [Manuel Atanasio Fuentes], ni a tantos otros asiduos concurrentes a las veladas, verdaderas lides en que las armas del talento y del ingenio se disputaban el lauro! ${ }^{47}$.

Semejante ejercicio de memoria le hizo reparar, en fin, en los cambios forzados por la derrota:

Después, en el reloj del tiempo sonó la hora de los grandes infortunios para el Perú y a los días de pasión febril por las letras han sucedido los de amargura y desaliento.

Triste, tristísima cosa es encanecer y vivir de recuerdos dolorosos, que la memoria en los viejos no es sino vasto cementerio en el cual las lápidas son los nombres de seres que nos fueron queridos.

Por eso, el libro que a la vista tengo melancoliza mi ánimo con la tristeza de las tumbas, y no veo ni quiero ver en él más que la corona de siemprevivas funerarias que el cariño de usted y el de Juana Manuela colocan sobre la losa de los muertos, pero no olvidados amigos y compañeros de labor literaria ${ }^{48}$.

47 Ibíd., p. vi.

48 Ibíd., pp. vi-vii. 
De esa manera, en términos cálidos y fraternos, Palma testimonió su admiración y lealtad a quien, a lo largo de muchos años de labor literaria, fue sin duda ninguna no solo su amiga y consejera sino su cómplice intelectual.

\section{ANEXO}

\section{"RICARDO PALMA"}

Mirando el último retrato de Ricardo Palma en su actual edad, he pensado por vez primera que ya para él la juventud ha pasado: de tal modo el alma del galano poeta guarda una juventud, una frescura que desbordan en su trato, en su pluma, y se reflejan en sus producciones más serias. Costaría a la mente asimilarlas a la edad madura, si a estas exquisitas dotes no se aunaran una grande energía, un austero estoicismo y una fuerza de voluntad incontrastable.

Bajo el modesto título de secretario privado del Presidente de la República, fue el mentor obedecido y acatado del irascible Balta.

No ha mucho, el más terrible día de la guerra, el fatal 15 de enero, cuando huido Piérola del campo de batalla dispersando las tropas de línea, el enemigo avanzaba sobre la fuerza de reserva situada en los reductos delante el [sic] pueblo de Miraflores, cuyos habitantes, mujeres y niños, huían despavoridos ante las bombas incendiarias, Palma, desde los reductos, mandaba prohibir a su esposa el abandonar esos muros que los suyos estaban defendiendo, y la ordenaba aguardar en su hogar la victoria o la muerte. 
Y cuando la aterrorizada joven, huyendo de su casa, saqueada y entregada a las llamas, con sus pequeños hijos en los brazos, llegaba a Lima a pie y exhausta de cansancio, él, cumplido hasta el fin el deber patrio, se reunió a ellos, serena la frente, fuerte el corazón, como en los días de la prosperidad.

Encargado por el gobierno de la reorganización de la Biblioteca Nacional, saqueada por el enemigo hasta el último volumen; quemadas sus vastas estanterías en las hogueras de los soldados acuartelados en su recinto, Palma se consagró al cumplimiento de esta misión con un patriotismo exaltado que despertó, no solo en América, sino en toda Europa, entusiastas simpatías.

Las academias, los palacios, las ricas residencias y los soberanos mismos abrieron sus tesoros bibliográficos al abnegado solicitante.

El rey Alfonso XII, que en sus últimos días recibió la demanda de Palma, hizo a Lima un valioso legado, flor de su real biblioteca.

Sin la pérdida de su colección de manuscritos, hoy la Biblioteca Nacional, gracias a la valiente solicitud de Palma, sería más rica que lo fue en los mejores tiempos del Perú.

Juana Manuela Gorriti.

En Prieto y Valdés, Casimiro (ed.). (1888?). Almanaque sudamericano para el año 1889. Buenos Aires: Ramón Espasa y Cía. 


\section{Bibliografía}

Batticuore, G. A. (1999). El taller de la escritora. Veladas literarias de Juana Manuela Gorriti. Lima: Buenos Aires (1876/7-1892). Rosario: Beatriz Viterbo Editora

2016). "La vida en las cartas: Ricardo Palma entre escritoras". Aula Palma dic. 2016, 15, pp. 253-274. Lima: Universidad Ricardo Palma

Batticuore, G. A. y Zuccotti, L. (1997). "Papeles de entrecasa. Juana Manuela Gorriti”. México. Recuperado http://lasa.international.pitt. edu/LASA97/batticuore.pdf

Gorriti, J. M. (1888?). "Ricardo Palma”, en Prieto y Valdés, Casimiro (ed.). Almanaque sud-americano para el año 1889. Buenos Aires: Ramón Espasa y Cía.

(2004). Cincuenta y tres cartas inéditas a Ricardo Palma. Fragmentos de lo íntimo. Buenos Aires-Lima: 1882-1891. Edición crítica, estudio preliminar, coordinación de dossier y diccionario a cargo de Graciela Batticuore. Notas en colaboración con César Salas Guerrero. Lima: Universidad de San Martín de Porres (Escuela Profesional de Ciencias de la Comunicación), Universidad de Buenos Aires (Instituto de Literatura Hispanoamericana, Facultad de Filosofía y Letras) y Patronato de la Casa Museo Ricardo Palma (Tarea Asociación Gráfica Educativa).

(2017a). "El banquete de la muerte", en su El mundo de los recuerdos. Edición de Mónica Cárdenas Moreno. Buenos Aires: EUDEBA, pp. 183-193.

(2017b). "Miraflores", en su El mundo de los recuerdos.

Edición de Mónica Cárdenas Moreno. Buenos Aires: EUDEBA. 


\section{Notas SOBRE LA COMPLICIDAD INTELECTUAL DE RICARDO PALMA Y JUANA MANUELA GORRITI}

(comp.). (1866). Corona poética ofrecida al pueblo peruano el 28 de julio de 1866. Lima, Imp. dirigida por J. R. Montemayor.

(comp.). (1890). Cocina ecléctica. Buenos Aires: Félix Lajouane Editor (Librería General).

(comp.). (1892). Veladas literarias de Lima. 1876-1877.

Tomo primero. Veladas I a X. Buenos Aires: Imp. Europea, 1892.

Gutiérrez de Quintanilla, Emilio (ed.). (1889). Cristián por Ricardo Palma y Cristina Román de Palma. Lima, abril 11 de 1889. Lima: Imp. de B. Gil.

Holguín Callo, O. (1982-1983). "Política y literatura en un impreso limeño de 1876". Boletín del Instituto Riva-Agüero, Lima: Pontificia Universidad Católica del Perú.

. (1994).Tiempos de infancia y bohemia. Ricardo Palma (18331860). Lima: Pontificia Universidad Católica del Perú.

. "Ricardo Palma en 1882-1892. De la defensa del Perú a la del español de América. Sus amistades argentinas", en Gorriti, Cincuenta y tres cartas inéditas a Ricardo Palma cit. Supra.

López Martínez, H. (1996). Sucedió hace un siglo. Segunda serie. Lima: Edición de El Comercio.

Miró, C. (1953). Don Ricardo Palma, el patriarca de las tradiciones. Buenos Aires: Editorial Losada, S. A.

Palma, A. (1933). Ricardo Palma. Buenos Aires: Ediciones Argentinas “Cóndor”, 1933.

(1935). "Veladas del ochocientos", en República Argentina. Homenaje del Ministerio de Justicia e Instrucción Pública a la memoria de la 
distinguida escritora peruana Srta. Angélica Palma. Buenos Aires: Talls. Gráfs. de la Penitenciaría Nacional.

Palma, R. (1870). Pasionarias. Havre, Tip. Alfonso Lemale.

(1874) "Carta tónico-biliosa a una amiga", en su Tradiciones.

Segunda serie, Lima: Imp. Liberal de El Correo del Perú.

(1877).Verbos y gerundios. Lima, Benito Gil.

(1899). "La bohemia de mi tiempo, 1848 a 1860 (confidencias)" (1886), en su Recuerdos de España, precedidos de La bohemia de mi tiempo. Lima: Imp. La Industria.

(1887). Poesías... Juvenilia. Armonías. Cantarcillos. Pasionarias.

Traducciones. Verbos y gerundios. Nieblas. Lima, Imp. de Torres Aguirre.

(2012). Carta a Juana Manuela Gorriti, de Lima y 10 nov. 1890, en Oguic, Sofía (comp.). Correspondencia entre Ricardo Palma y Adolfo Pedro Carranza (Buenos Aires), Embajada del Perú en Argentina; Lima: Biblioteca Nacional del Perú.

(1892). "[Carta-prólogo]" a Julio F. Sandoval, en Gorriti, Veladas literarias de Lima cit. supra, pp. v-vii.

(1911). Poesías completas. Barcelona, Casa Editorial Maucci, (1949). Epistolario. 2 vols. Lima: Editorial Cultura Antártica S. A.

Paz Soldán, M. F. (1879). Biblioteca peruana. Lima: Imprenta Liberal.

Román de Palma, C. (1890). "Pachamanca", en Gorriti, Cocina ecléctica cit. Supra.

Salas Guerrero, C. (2006). “Juana Manuela Gorriti y el Perú”. Revista de la Casa Museo Ricardo Palma, Lima, dic, № 6. 
Sotomayor Martínez, E. (comp.). (2017). Pensar en público. Las veladas literarias de Clorinda Matto en la Lima de la posguerra (1887-1891). Lima: Biblioteca Nacional del Perú.

Varillas Montenegro, A. (201 1-2012) "Política y cultura en una década de esplendor, la de 1870”. Revista Histórica, Lima, № 45.

Recibido el 19 de diciembre del 2018 Aceptado el 21 de enero del 2019 